\title{
Features of consumer behavior of Russian tourists in duty-free shops
}

\author{
Natalia Strekalova ${ }^{1}$, Elena Korchagina ${ }^{2, *}$, and Larisa Desfonteines ${ }^{2}$ \\ ${ }^{1}$ Herzen State Pedagogical University of Russia, St. Petersburg, Russia \\ ${ }^{2}$ St. Petersburg Peter the Great Polytechnic University, St. Petersburg, Russia
}

\begin{abstract}
In the modern world, a new category of travelers (global shoppers) has appeared. They are people who spend their time for shopping on abroad trips. The article considers the problem of understanding the consumer behavior of Russian tourists (Russian global shoppers) in duty-free shops. The purpose of the study is to identify the features of consumer behavior, motives and habits of Russian tourists when shopping at duty free stores at airports. A pilot study was conducted by questionnaire survey at the airport. The results of the study showed that Russian tourists consider shopping (duty free) as part of their trip abroad. They are looking for a favorable price / quality ratio. Many of them do not plan their shopping in advance, but adhere to certain budget restrictions. The paper offers suggestions to improve customer satisfaction. The results of the study are useful for business persons and marketing managers in the international trade sphere.
\end{abstract}

\section{Introduction}

In the modern world, there is a dynamic development of the retail industry for international travelers (duty free and travel retail). The economy globalization, tourism development, the growth in the airlines number, the modernization of old and the opening of new airports over the past two decades have led to $5 \%$ annual increase in the traffic of tourists flying by air. This growth was largely facilitated by the tourists from developing countries, including Russia. According to the results of studies, the volume of global retail sales in the field of duty free \& travel retail in 2018 increased by $12.9 \%$ compared to the same period of previous year and reached $\$ 78.96$ billion. The airport stores have the largest share of global sales. They have reached $\$ 41.7$ billion with 9.3\% annual average increase [1].

Currently, a new category of travelers (global shoppers) has appeared. They are people who spend their time for shopping while traveling abroad. They see shopping as part of their journey. These consumers form the core of the duty free and travel retail market. According to the results of research, such travelers spend an average of about 3 hours in hubs (airports) around the world, which allows them to set aside time for shopping at airports. Understanding the needs of global shoppers and meeting their expectations is essential for the business. With the increasing number of outbound tourist trips of Russian

* Corresponding author: elena.korchagina@mail.ru 
citizens to foreign countries, the influx of Russian buyers (Russian global shoppers) is increasing. Duty free shopping becomes an important component of international trip for these people.

An analysis of the literature showed that studies of the consumer behavior of Russian tourists traveling abroad are still not sufficiently represented in the works of Russian and foreign authors $[2,3]$. Global shoppers' researches made by large international consulting and advertising companies, as a rule, have a purely practical, commercial focus [4]. All this determines the importance of conducting research on consumer behavior of Russian tourists (global shoppers) when making purchases in duty free stores.

\section{Problem statement and research methodology}

In duty free stores at international airports, a large number of products of various brands are presented, which creates additional difficulties for manufacturing companies in promoting brands, highlighting their products on store shelves, and building effective communications with customers $[5,6]$. At the same time, there is a problem associated with understanding the behavior of consumers (global shoppers) among Russian tourists, their habits and crosscultural characteristics during shopping at the airport. This makes it difficult to promote brands, build communications and effectively service this segment of consumers [7].

The purpose of the study is to identify the peculiarities of consumer behavior of Russian tourists that determine the choice and purchase in the duty free stores at airports, as well as provide suggestions to increase customer satisfaction. The subject of the study is the consumer behavior of Russian tourists in the duty free stores at the airports. The object of the study is Russian tourists (from 18 years and older). The data collection method used is a questionnaire survey.

The following hypotheses were put forward during the study:

$\mathrm{H} 1$ : duty free shopping at international airports is considered by Russian tourists as part of their trip;

$\mathrm{H} 2$ : tourists are looking for a favorable price / quality ratio;

N3: tourists do not plan their shopping in advance, but adhere to certain budgetary restrictions.

\section{Results and discussion}

According to Rosstat, the number of outbound tourist trips of Russian citizens to foreign countries amounted to almost 42 million (2018), and for the first three quarters of 2019 35.2 million [8]. The dynamics of the number of outbound trips of Russians over the past six years is shown in fig. 1 . The analysis shows that a significant decline in the number of abroad trips of Russian citizens was observed in 2015-2016, due to the influence of many factors: the aggravation of the political situation in the world, the imposition of economic sanctions against Russia, as well as economic factors, including depreciation of the ruble exchange rate, falling solvent demand of Russian citizens, their reorientation to domestic tourism. However, over the past three years, there has been a tendency towards an increase in the number of trips of Russian citizens to foreign countries. 


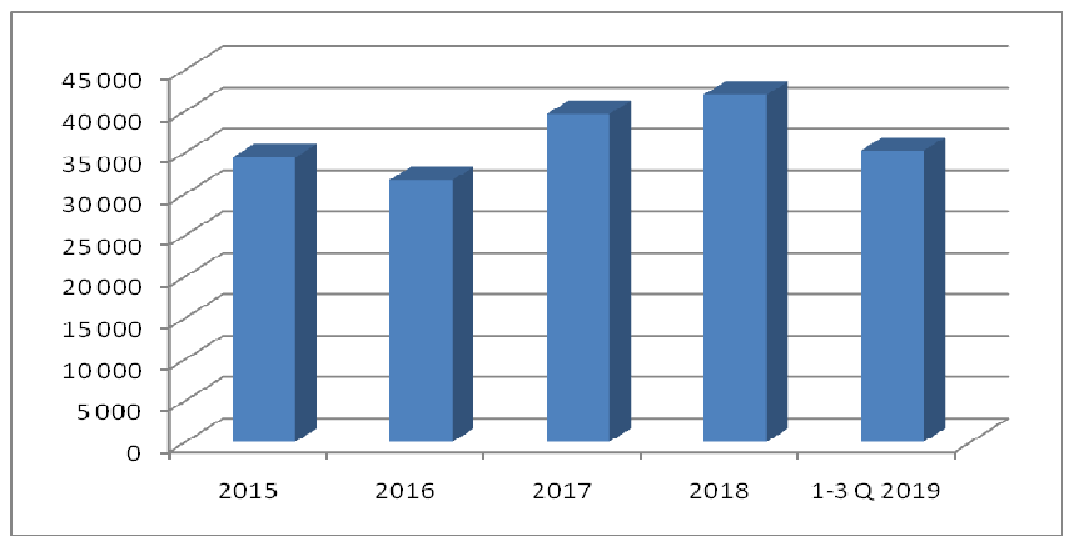

Fig. 1. Number of outbound tourist trips of Russian citizens to foreign countries, total thousands.

The empirical basis of the study was an array of data collected during a questionnaire survey (face-to-face) of Russian travelers (global shopper) over 18 years of age. The survey was conducted at the Pulkovo Airport (St. Petersburg). Moreover, we used following selection criteria for respondents: 1) age over 18;2) experience of traveling abroad; 3) customer experience in duty free stores. It is important to note that duty free shops are located in the "sterile zone" of the airport, access to which is strictly controlled. Passengers can get into it only after passing through passport control, passenger check / inspection points, then they flying by plane to another economic zone. 114 people at the age of 18 years and older were interviewed. 15 of them (13\%) indicated that they had not previously traveled abroad. 99 people had such experience. Among them: 29\% made about 1-2 trips per year, $49 \%$ traveled less than 1 time per year, $22 \%$ traveled 2 times per year or more (fig. 2 ). At the same time 16 people have said that they had not made purchases in duty free stores previously. As a result, our sample included 83 people (global shoppers) that regularly traveled abroad and made purchases in the duty free stores.

To conduct the survey, a questionnaire of 20 questions was developed, including inputfilter questions for the purpose of selecting respondents (age, experience traveling abroad and shopping experience in duty free stores). The content of the main part of the questionnaire recorded the following information:

- frequency of shopping in the duty free stores at the airports;

- categories of goods and brands that are usually bought;

- reasons for duty free visiting stores and buying goods in them;

- motives and features of customer behavior in duty free stores;

- factors affecting the choice and purchase of goods;

- presence / absence of preparation for visiting the store (shopping list);

- personal impressions of shopping;

- approximate cost of purchases in duty free stores;

- suggestions for improving service at duty free stores;

- socio-demographic characteristics of the respondent.

$73 \%$ of our respondents were women and $27 \%$ were men (fig. 3 ). The gender structure of the sample reflects the real situation when women are the most active buyers in the duty free stores. Moreover, all our respondents lived in large Russian cities with a population of over one million people: St. Petersburg, Moscow, Yekaterinburg, Irkutsk, Kazan, Saratov, etc. 


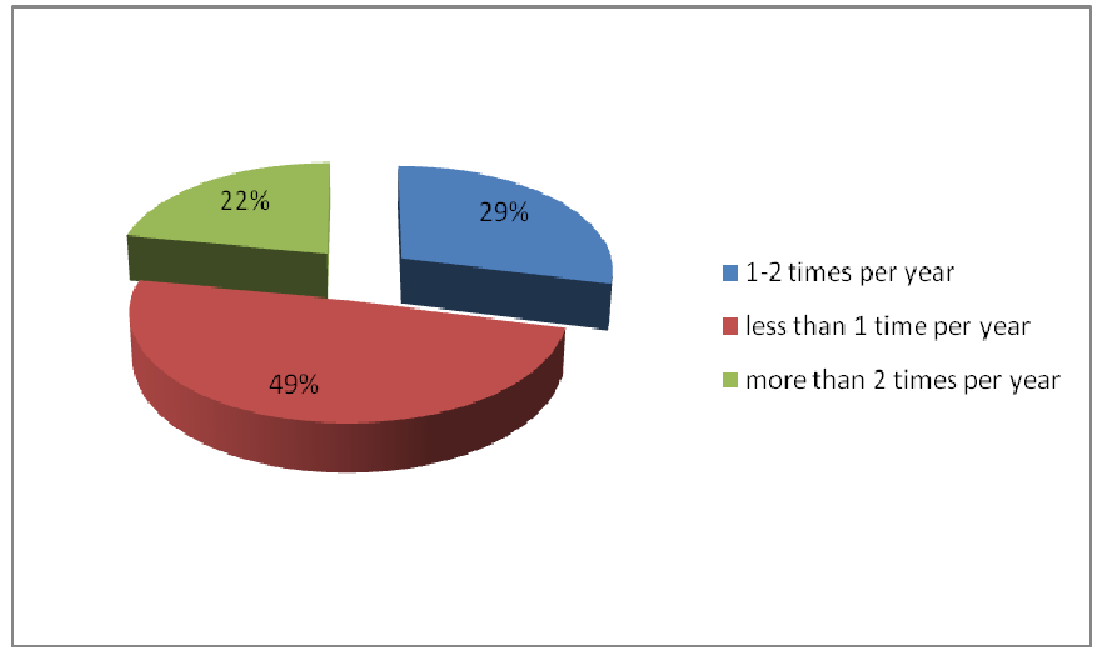

Fig. 2. Distribution of respondents by frequency of departure abroad (\%).

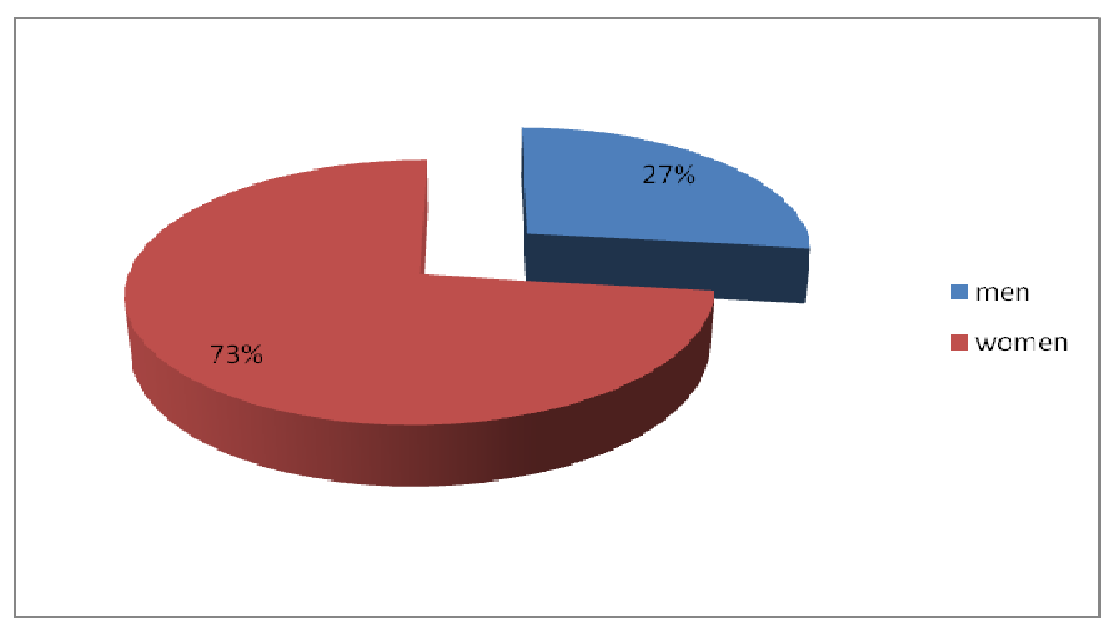

Fig. 3. Distribution of respondents by gender.

Four age groups were identified: respondents from 18 to 25 years old; from 26 to 35 years old; from 36 to 50 years old and 51 and older. At the same time, the majority of respondents were young people under 35. Moreover, 49\% of respondents belonged to the age cohort from 18 to 25 years. The second and third age groups included 19\% of respondents each. The fourth age group included 3\% of respondents (fig. 4). We also have analyzed occupation of our respondents. $46 \%$ of them were students, $37 \%$ were employees, $11 \%$ were entrepreneurs or owners of their business, and 6\% were homemakers (fig. 5). 


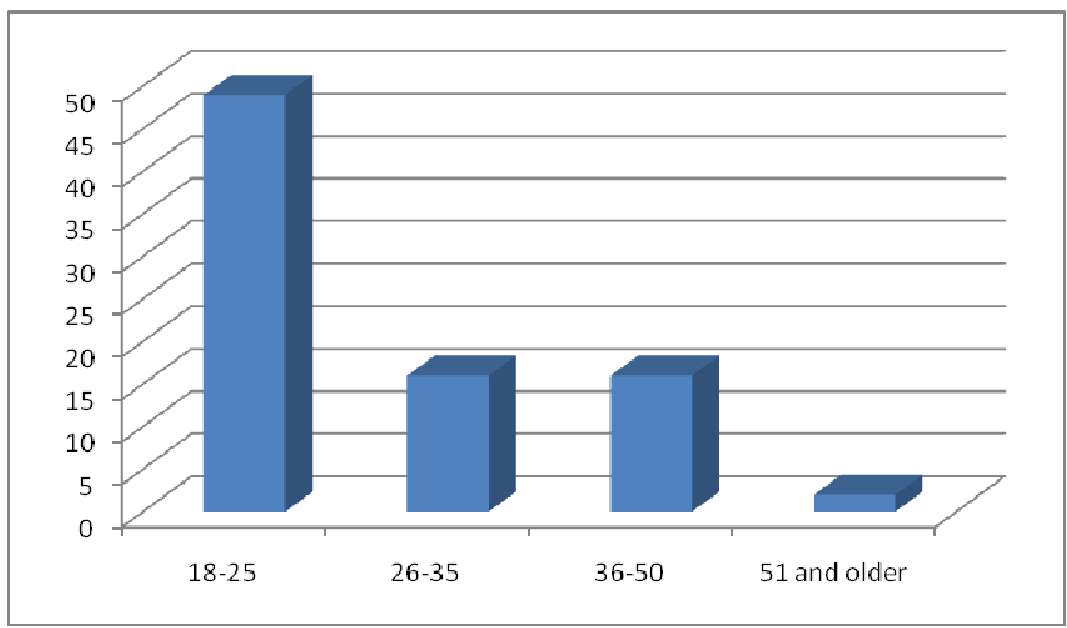

Fig. 4. Distribution of respondents by age.

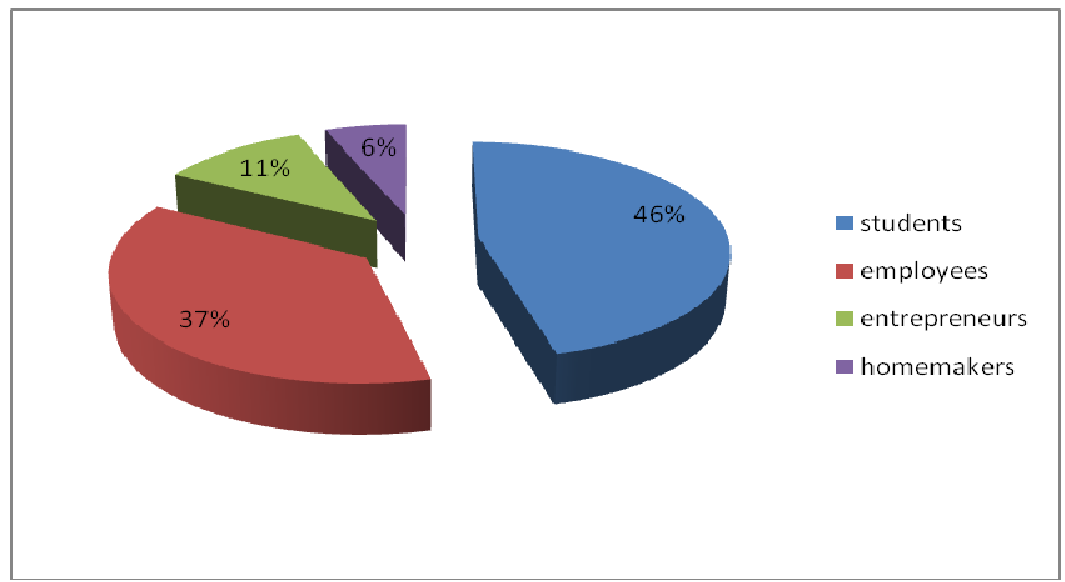

Fig. 5. Distribution of respondents by occupation.

The answer to the question "For whom are the purchases made?" involves multiple choices. The survey results showed that most of Russian tourists have made purchases in duty free stores for themselves ( $84 \%$ of respondents). At the same time, $27 \%$ of respondents have said that they buy goods not only for themselves, but also as a gift to relatives or friends, and $14 \%$ indicated that they have done this at the request of their friends (fig. 6). 


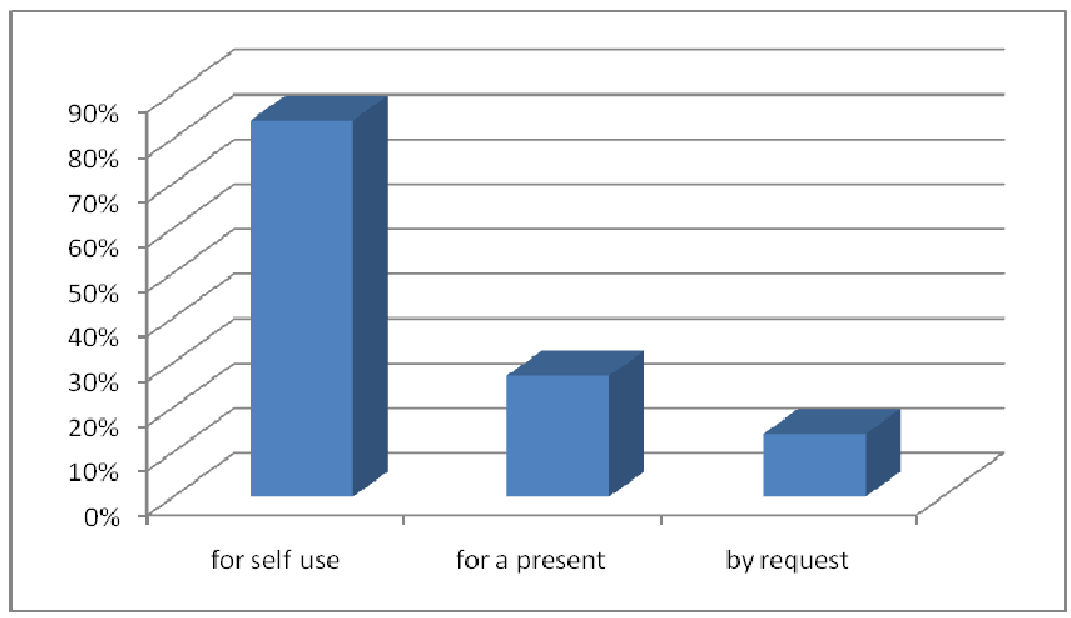

Fig. 6. Purpose of purchased goods in duty free stores.

The question of shopping preferences also suggested multiple choice answers. According to respondents' answers there are two key product categories in the duty free shopping baskets of Russian travelers: alcohol (71\% of respondents' answers) and cosmetics and perfumes (59\%). Moreover, the latter product category is bought by both women and men. $40 \%$ of respondents have indicated that they buy sweets and confectionery, and 5\% of respondents have made purchases of accessories (fig. 7).

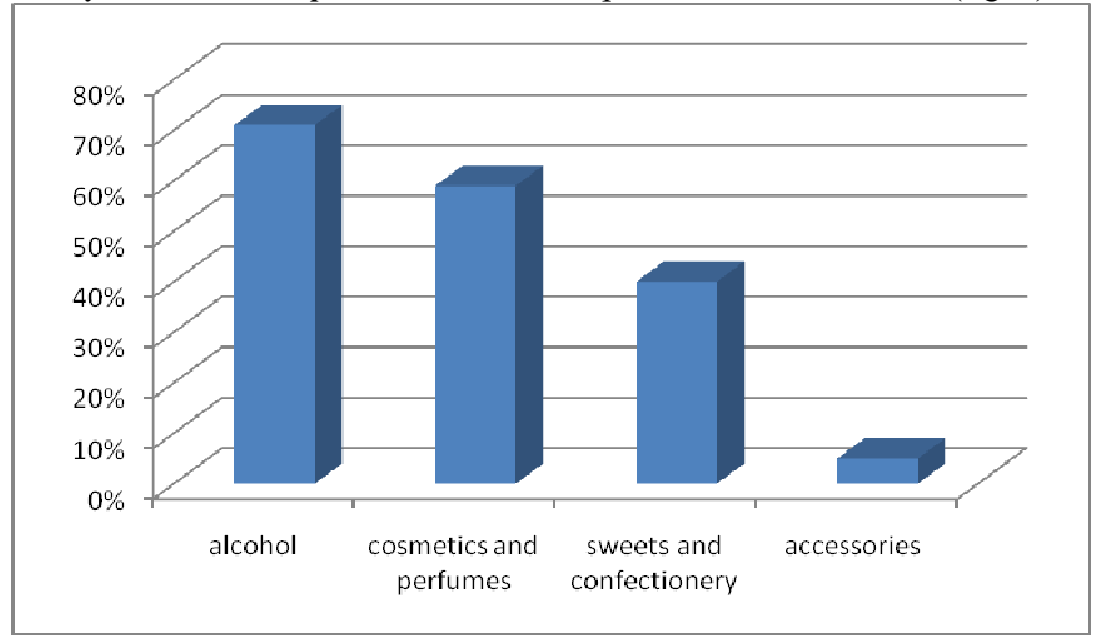

Fig. 7. The most frequently purchased product categories in the duty free stores.

In the course of the study, we tried to find out what motivates Russian tourists to make purchases in the duty free shops (fig. 8). Most (55\%) of respondents indicated that in the duty free shops they have bought goods with high quality and good price. Indeed, buying goods at duty free shops at the airport allows tourists to save costs. At the same time, $40 \%$ of respondents consider the quality of goods in stores (duty free) higher than in the domestic market. The image of stores convinces them that they will not buy a fake (counterfeit). Thus, the data obtained confirm our earlier assumption (hypothesis H2) that the main motive for the buying behavior of Russian tourists in the duty free stores is to search for a better offer in terms of price / quality.

Another $24 \%$ of respondents believed that they could not find the similar products in their regions in Russia. Indeed, the goods of world brands that can be seen in the branded 
stores of international airports are considered prestigious, which increases their value in the eyes of the consumer and stimulates the purchase. Also goods with a limited offer (special goods, with holiday packaging, etc.) or travel sets are very attractive for the Russian travelers because the purchase of such goods is available only at the airport / on board the aircraft. At the same time, $40 \%$ of the Russian travelers have indicated that they often just wanted to spend the time in the duty free shops waiting for their plane departure. At the same time, if they find an interesting offer for themselves, they make a purchase.

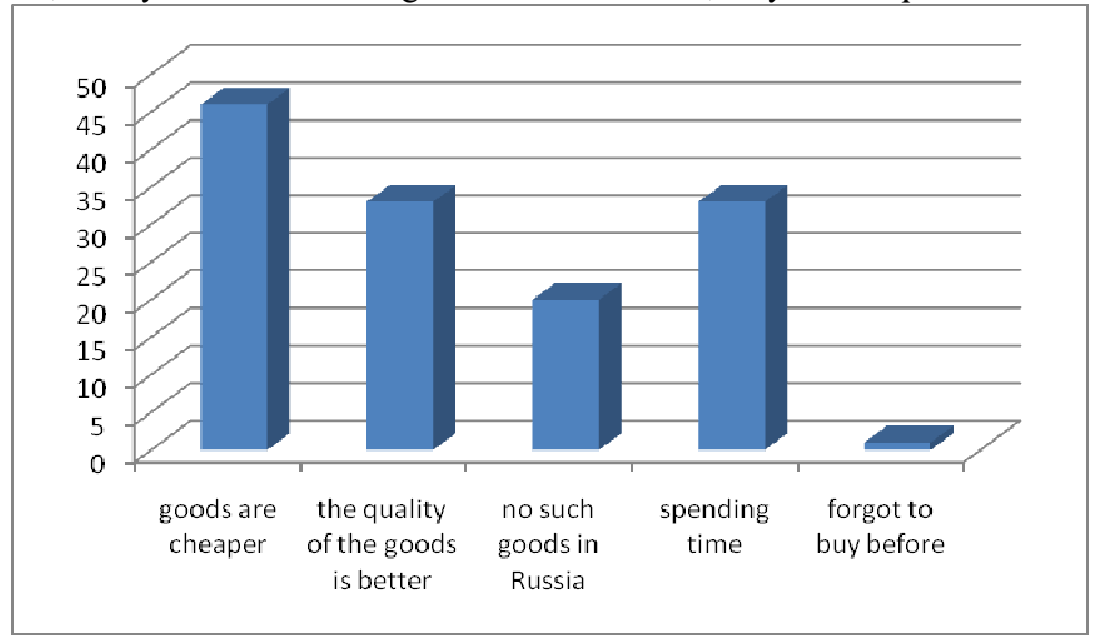

Fig. 8. The main motives of buyers in the duty free stores.

The next research question was about the types of consumer behavior of Russian tourists in the process of visiting duty free shops (fig. 9). More than half of the respondents (44 answers, 53\%) consider themselves to have the "emotional" type of behavior. The desire to pass the time at the airport was presented in the questionnaire with the phrase: "I wander, maybe I'll see something." People of this type make purchases spontaneously, often impulsively, under the influence of a momentary mood or curiosity (like some product, attractive packaging). Women have this type of behavior more often than men. Another part of respondents (40\%) demonstrates the "traditional" type of behavior. People of this type "know exactly what they want to buy". They prefer to buy goods already tested and familiar to them. They reproduce their usual purchasing behavior. Only a small part (7\%) of the respondents indicated that they communicate with consultants before making a purchase. As a rule, such people tend to focus on the opinions of others, to listen to the advice of friends / acquaintances or consultants. This is a "listening" type of behavior. The questionnaire data allow us to assume that most Russian tourists do not need communication with consultants. However, perhaps this is also due to the language barrier. 


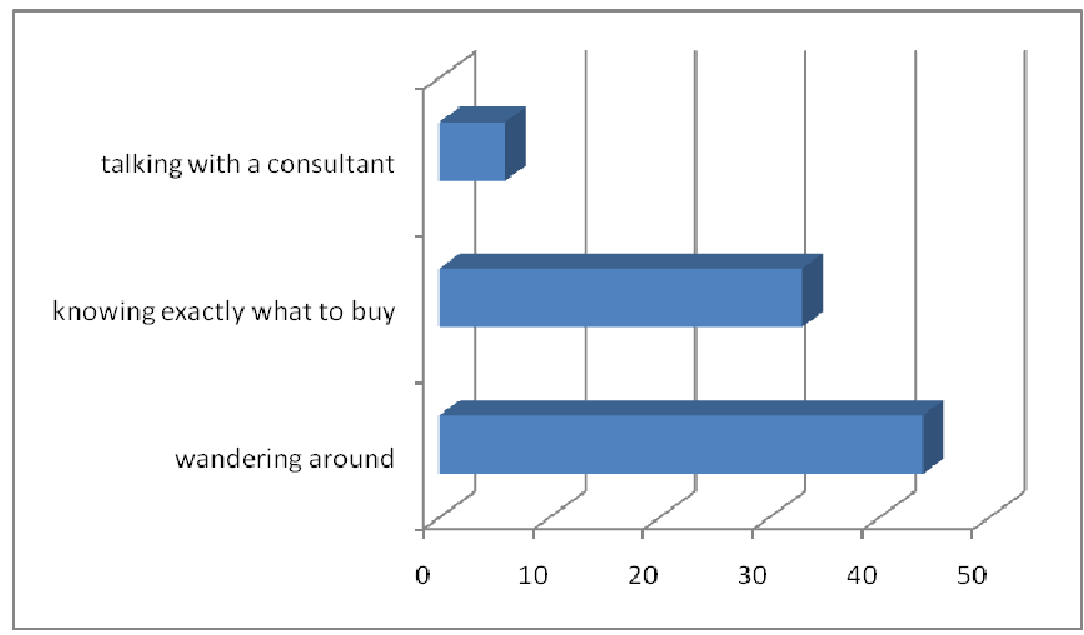

Fig. 9. Types of consumer behavior of Russian tourists in the duty free stores.

Next question was about the factors affecting the choice and purchase of goods (fig. 10). The majority of respondents $(57 \%)$ said that choosing a product they have relied only on their personal consumer experience. The second most frequently mentioned factor for many respondents $(31 \%)$ was the reduction in prices (discounts) for goods in duty free stores compared to prices in the Russian market. Limited supply of goods (especially for the airport, limited edition) was a significant factor for $29 \%$ of respondents. Almost a quarter (24\%) of respondents was affected by their friends' advices and to a lesser extent by the advice of consultants (10\% of buyers). At the same time, $19 \%$ of respondents opt for prestigious products if the price is lower (more affordable) than usual.

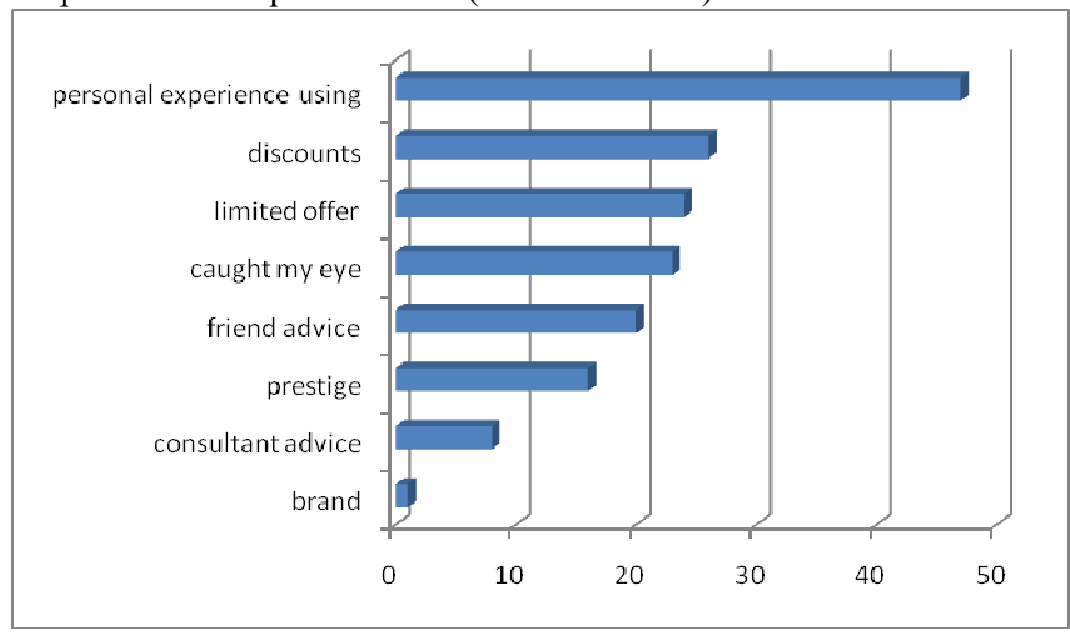

Fig. 10. Factors affecting the selection and purchase of goods.

The next question was about the preparation for shopping. Half of the respondents $(51 \%)$ said that they didn't make any special preparations for shopping in duty free stores. It means that Russian tourist tend to more impulsive shopping abroad. Almost half of the respondents $(47 \%)$ indicated that they allocate a certain amount that they are willing to spend on purchases at the airport and try to stay on budget. Only a small part (7\%) of the respondents made a specific shopping list. Thus, the data obtained confirm our earlier 
hypothesis (H3): Russian tourists do not plan their shopping in advance, but adhere to certain budget restrictions.

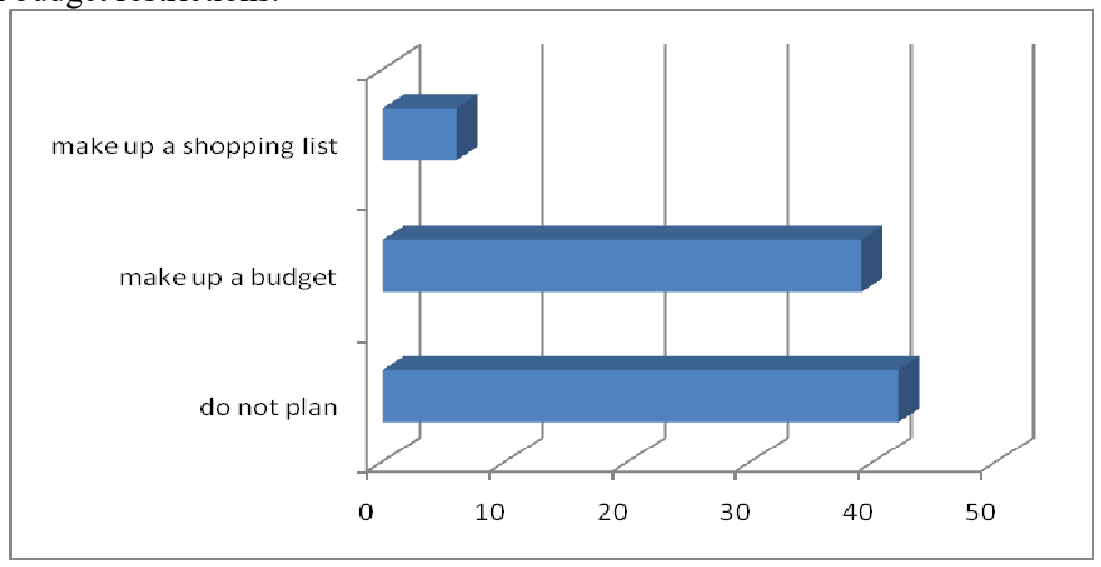

Fig. 11. Preparation for shopping.

According to our research results, almost half (43\%) of the respondents noted that they spend from 2 to 5 thousand rubles on purchases in the duty free stores. About a third $(28 \%)$ of respondents can spend on purchases only a small amount - up to 2 thousand rubles. Another $15 \%$ indicated that they were ready to spend from 5 to 10 thousand rubles, and only $14 \%$ of respondents were ready to spend more than 10 thousand rubles (fig. 12).

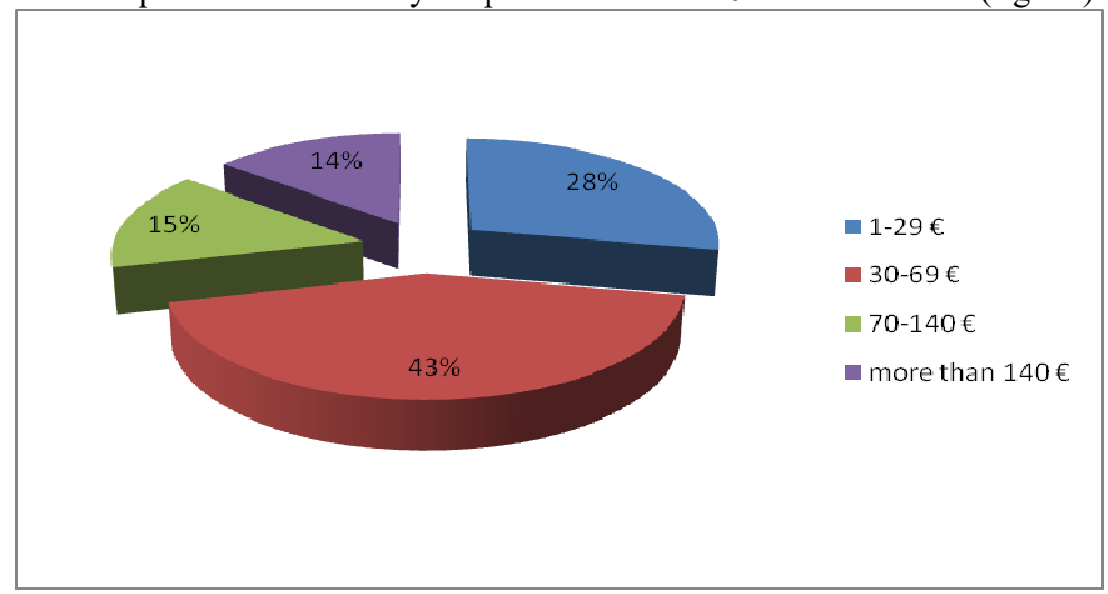

Fig. 12. Average check of purchases of Russian tourists in the duty free stores.

Consider the answers to an open question: what creates a pleasant shopping experience? According to the respondents, a pleasant impression of shopping in the duty free shops is created by:

- Price reduction. Promotions and discounts are important factors, and cost savings are an important incentive to visit and buy at the duty free stores.

- Quality products. Distrust in the quality of domestic goods provides an influx of tourists to duty-free shops. The status of the store abroad increases the confidence of the buyer in the quality of the goods offered by him.

- Staff. Unobtrusiveness, competence, "pleasant communication" of consultants and security guards allow customers enjoy shopping. However, if necessary, staff should always be ready to provide assistance and necessary clarifications. 
- The atmosphere of the store. Properly built logistics, no queues at the checkout, a pleasant atmosphere and design create a unique experience from shopping.

- Anticipation of travel pleasure and established traditions. For many Russian travelers the duty free shopping has become a tradition when traveling abroad.

- Gifts with purchase. According to the respondents' answers, pleasant gifts at the end of the purchase make it more enjoyable. The same effect can be reached by the gifts in the case of a large number of goods purchase.

- The opportunity to pleasantly spend respondents' time at the airport.

So, the survey confirms hypothesis (H1): duty free shopping at international airports is considered by Russian tourists as part of their trip.

Thus, all three hypotheses were confirmed in our study.

The main proposals for increasing the attractiveness of the duty free retail channel and the satisfaction of Russian travelers are as follows:

1. Offering discounts and / or carrying out promotions on goods, as well as highlighting these offers.

2. It is desirable to reflect on the price tag the benefits that the buyer will receive. In the duty free shops, buyers hope to see a lower price than in the home market.

3. Forming the sets including several goods in small volumes in individual packaging. Buying such a set will allow customer to make gifts without violating the integrity of the package.

4. Wrap gifts in the duty free shops. The special gift wrapping rack saves customers' time and motivates them to buy gifts for friends / relatives on special occasions.

5. Offering national souvenirs as a gift for purchase. The presence of a national identity on the product will form pleasant memories among tourists.

6. Product tasting. The tasting of the product by the customers will allow them to form their own opinion about the product, which encourages them to buy it.

7. Paying more attention to communications in the duty free store. The professionally trained staff with attentive Russian-speaking consultants helps to resolve emerging problem situations with Russian tourists.

8. Emphasizing customers' attention to the benefits of the duty free shopping in all advertising messages.

9. Creating a list of "best sellers" among Russian tourists. This will help customers in navigation among a large number of offers and buying products recommend by their compatriots.

10. Highlighting zones of certain brands.

The implementation of these proposals will create additional value in the duty free shops; improve perception, increase interest and satisfaction of the Russian customers.

\section{Conclusion}

The results of the study showed that a new category of travelers (Russian global shoppers) has appeared and continues to form in Russia. These people spend time on shopping during their trips abroad, prefer shopping in duty free stores and consider it as an important part of their trip.

The purpose of the study was to identify the peculiarities of consumer behavior of Russian tourists in duty free shops at airports, and to offer suggestions for increasing customer satisfaction. The obtained results confirmed all three hypotheses of our research. Russian tourists consider duty free shopping at airports as part of their travel abroad. They are looking for a better offer in terms of price / quality. Many of them do not plan their shopping in advance, but adhere to certain budget restrictions. 
The study revealed the main types, preferences, motives and characteristics of consumer behavior of Russian tourists in duty free shops at airports. Half of the respondents refer to the "emotional" type of behavior and make purchases often impulsively. The other part demonstrates a "traditional" type of behavior, prefers buying previously tested products, based on their personal experience. The main motives for the buying behavior of Russian tourists in duty free stores are obtaining savings, buying goods of higher quality, favorable offers in terms of price / quality. The research showed that in the shopping basket of Russian travelers three main product categories prevail: alcohol, cosmetics and perfumes, sweets and confectionery.

On the basis of research results we have developed the set of recommendations for increasing the interest and consumer satisfaction of Russian customers in duty free stores. Promising areas for further research may be related with more in-depth and large-scale studies of consumer behavior of Russian travelers, as well as comparative analysis of crosscultural characteristics of the global shoppers' consumer behavior.

\section{References}

1. Generation Research (2018) URL: https://www.moodiedavittreport.com/global-dutyfree-travel-retail-sales-up-12-9-in-2018-says-generation-research/

http://www.generation.se/ (Access date: October 30, 2019)

2. N. Kondrasheva, Problems of economics and management 11, 40-44 (2014)

3. G. Timokhina, E. Kulikova, Russian Entrepreneurship 16, 152397-152406 (2015). DOI: 10.18334 / rp.16.15.561

4. JCDecaux launches Global Shopper Connections 2, revealing new insights into the travel and shopping habits of international shoppers (2019) URL: https://www.jcdecaux.com/blog/launching-jcdecaux-global-shopper-connections-2uncovering-shopping-habits-international (Access date: October 30, 2019)

5. L. Desfonteines, E. Korchagina, A. Varnaev, J. Semenova, IOP Conf. Ser. Mater. Sci. Eng. 497(1), 012117 (2019). DOI: https://doi.org/10.1088/1757-899X/497/1/012117

6. I. Krasyuk, T. Kirillova, S. Sergeev, E3S Web of Conferences 91, (2019). DOI: $10.1051 / \mathrm{e} 3$ sconf/20199105007

7. I. Krasyuk, A. Kobeleva, P. Mikhailushkin, G. Terskay, A. Chuvakhina, Espacios 39(31), 19-30 (2018)

8. Retail trade, public services, tourism. Rosstat URL: https://www.gks.ru/folder/23457 (Access date: October 30, 2019) 